\title{
Pandemia, mentalidad peruana y el Ser nacional: claves para la refundación nacional pos-bicentenario
}

\author{
Pandemic, Peruvian mentality and the national Being: keys to the post- \\ bicentennial national re-foundation
}

Pável Abarca Jiménez ${ }^{1}$

\section{Revista \\ Educación y Sociedad}

Citar como: Abarca, P. (2020).

Pandemia, mentalidad peruana y el Ser nacional: claves para la

refundación nacional posbicentenario. Revista Educación y

Sociedad, 01(02), 19-30.

doi: $10.53940 /$ reys.v1i2.56

Artículo recibido: 27-07-2020

Artículo aprobado: 07-11-2020

Arbitrado por pares

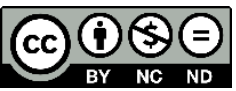

\section{ACEES}

\section{Resumen}

El presente artículo analiza la problemática de la mentalidad peruana en el contexto de la pandemia y cómo la presencia de una nueva normalidad patológica determina la mayor vulnerabilidad del país para enfrentar cualquier tipo de crisis. Se buscó demostrar que la corrupción en el Perú no sólo se ha instalado en estructuras e instituciones, sino también, en la mentalidad nacional y es parte de la convivencia social en las grandes ciudades del país. Esto implica la corrupción sistémica del Ser nacional y requiere una refundación moral y educacional de cara al bicentenario.

Palabras clave: pandemia, mentalidad peruana, ser nacional

\section{Abstract}

This article analyzes the problems of the Peruvian mentality in the context of the pandemic and how the presence of a new "pathological normality" determines the country's greatest vulnerability to face any type of crisis. It is shown that corruption in Peru has not only been installed in structures and institutions, but also in the national mind and is part of social coexistence in the country's great cities. This implies the systemic corruption of the national Being and requires the moral and educational re founding of the national Being for the bicentennial.

Key words: pandemic, peruvian mentality, being national 


\section{Introducción}

Una de las imágenes más chocantes para el pueblo peruano, durante la pandemia, fue ver a algunos pobladores haciendo fila y comprando cerveza. Algo que generó perplejidad, asombro y, en muchos casos, indignación. Las preguntas lógicas ante la situación fueron: ¿Qué pasa por la mente de estas personas?, ¿se dan cuenta realmente de lo que están haciendo? Pero, con la extensión del aislamiento social obligatorio, además del arrinconamiento de los más vulnerables a la precariedad material (o la reprecariedad material), producto del desempleo y la ruptura de la cadena de pagos, hizo carne una vez más nuestra dinámica social republicana sempiterna "ninguneadora", cuya expresión está en la prosa de José Carlos Agüero (2020):

Podemos escuchar a representantes de las élites estigmatizar a quienes salen a buscarse la vida asumiendo el riesgo del contagio, sin tomar en cuenta que para sobrevivir a la enfermedad primero hay que sobrevivir, a secas (...) La pandemia nos muestra en nuestra desnuda honestidad. No descubre nada, tampoco devela, solo hace un zoom grotesco sobre los viejos agravios (...) La gente culpable, inconsciente. $Y$ poderosamente inmoral, pues rompe los supuestos pactos de convivencia, de protección mutua, los acuerdos de convivencia de la especie. Y a esta plebe se le toma fotos, se la insulta. La acorrala la prensa y la policía, emboscada en mercados porque ha salido, ha escapado a la restricción, a la orden. Desde la ventana de un edifico de clase alta, se suelta un agravio que se replica por las redes antes la vista de un vendedor insurrecto. Que no está en su lugar. Ni físico porque ese no es su barrio. Ni legal porque debería estar en su casa sentado, aguantándose el hambre y el de su familia. Ese descolocado genera el ninguneo clásico pero enardecido, legitimado, que no necesita esconderse. Y se convierte en asco y pedido de represión (supresión) (2020, pp. 31-32).

Sin duda alguna, esta crisis sin precedentes ha sido una forma cruda de desnudar severos problemas sociales, sanitarios, económicos y políticos, junto a profundas cicatrices idiosincráticas, culturales y educacionales. Como diría el sociólogo peruano Nugent (2020), se han visto pasar "doscientos años a través de cuarenta días" (p. 149). ¿Será, como señala el filósofo británico Scruton (2010), que los últimos decenios en el Perú hemos vivido una promesa económica cargada de un "optimismo sin escrúpulos", donde el ideal del crecimiento económico nos vino a considerar como el "milagro económico" de Sudamérica sin analizar concienzudamente si este aumento cuantitativo se tradujo en bienestar y capacidad para el buen vivir? ¿Nos auto-engañamos?

La pandemia postula al pesimismo como la posibilidad de tratar los asuntos humanos con equilibrio y sensatez (Scruton, 2010), sin triunfalismos propagandísticos de tipo ideológico. Uno afianzado en la evidencia histórica y la templanza, no un nihilismo que hable de la nada cuando, en esta situación mundial, nos jugamos todo; porque, producto de la pandemia, estamos ante la crisis mundial más grave desde 1870, según el Banco Mundial.

¿Es el país una promesa incumplida? ¿o, como lo plantea el sociólogo peruano Vergara (2018), solo se cumplió la promesa neoliberal del crecimiento económico y el bienestar material?, ¿se dejó al libre albedrío de cada peruano su formación ciudadana, conducta cívica y estructuración valórica? El irrespeto a la ley, pensarla como una sugerencia y no una obligación, es la evidencia de una sociedad cívicamente no saludable. La conversión de una economía de mercado a una sociedad de mercado absolutiza lo económico y lo material, convirtiendo al Homo Sapiens en Homo Economicus. En esta perspectiva, debemos situarnos en lo sostenido por Vergara (2018), ser unos ciudadanos sin República, o en la perspectiva de Flores (1997), ser una República sin ciudadanos. Sin embargo, bajo la lógica economicista, necesitamos de un Perú S.A. con status de "órgano sexual del capital” (reproducción del capital como 
finalidad suprema del hombre) en palabras del filósofo surcoreano Byung-Chul Han (2014), donde la premisa fundamental de la vida sea vivir bien, la mera vida y no tanto la vida buena, el buen vivir. Pero, la crisis pandémica nos interpela y enrostra una necesidad vital para el Ser nacional peruano: necesitamos mejores ciudadanos. Es un desafío nacional, institucional y educacional. Aquí, se marcará un punto de quiebre en el imaginario colectivo de nuestro país. La crisis y su resaca económica coincidirán en la línea del tiempo con otro evento de suprema trascendencia para el alma de la peruanidad: la celebración del Bicentenario de la Independencia del Perú.

El presente inmediato nos lleva a la pregunta: ¿por qué, si el Perú desde un inicio hizo las cosas tan bien, al final todo salió tan mal? La OMS reconoció a nuestro país por ser uno de los primeros en acatar sus recomendaciones sanitarias supranacionales, pero a julio del presente año somos el quinto país en el mundo con mayor número de casos confirmados, solo después de EE.UU., Brasil, Rusia e India. El precio a pagar por el confinamiento y rompimiento de la cadena de producción, de distribución y pagos es dejar al país al borde de un colapso económico sin precedentes, incluida la pérdida masiva de empleos y, según Conexión ESAN (2020), un consiguiente ascenso a más de 4 millones de desempleados al final del presente año. De igual forma la pobreza, de acuerdo al economista peruano Gonzáles Izquierdo, pasará de $20 \%$ a $27 \%$, sin dejar de atender la advertencia de la ONU: millones de personas en Latinoamérica camino a la escasez y hambruna. Es decir, recibiremos nuestro Bicentenario bajo el acecho de una sombra lúgubre agigantada por nuestra historia, el retrato de país adolescente (Sánchez, 1963), el ADN institucional precario, la corrupción endémica-metastásica, una lacerante desigualdad social y mentalidad nacional cuasi-ciudadana. Esto último traducido en la demostrada y peligrosa conducta cívicamente antisocial. De ahí, el presente trabajo trata de responder las siguientes preguntas: ¿Somos una sociedad cívicamente saludable?, ¿Cómo influyeron los antivalores ciudadanos en el agravamiento de la crisis sanitaria?, ¿nuestra conducta ciudadana nos cohesiona o divide ante una crisis?, :puede ser el Bicentenario una oportunidad para re-pensar nuestra idiosincrasia, la mentalidad colectiva y los valores nacionales o un espacio-tiempo para generar un nuevo contrato social cívico-educacional?, ¿será en vano esta crisis y tendremos como única motivación regresar a la antigua normalidad sin ningún espíritu crítico de lo que fuimos y lo que somos como peruanos?, ¿podemos aprovechar la narrativa de la "nueva normalidad" para replantear profundamente nuestra conducta ciudadana y educación? Esto nos lleva a la cuestión existencial más grave para la nación peruana pos-bicentenario, planteada radicalmente por el peruanista arequipeño Víctor Andrés Belaunde (1931) ¿cuál será nuestra nueva mística, nuestro nuevo centro de gravedad espiritual? Lo cierto es que hoy una advertencia cobra dramática realidad: "Raza que renuncia a comenzar se condena a no llegar a ser jamás a una valoración intrínseca en el devenir de la historia” (Orrego, 1929, p. 1).

\section{Desarrollo del trabajo}

\section{Mentalidad peruana y el Ser nacional de cara el Bicentenario}

Si hiciéramos un ejercicio imaginario, juntando en el presente a todos los que tuvieron como objeto de estudio al Perú para discutir sobre el Ser nacional y su configuración a lo largo de décadas, podríamos tener una visión cabal de por qué el peruano piensa, siente y actúa como lo hace; y por qué en el contexto de la pandemia nuestra idiosincrasia ha sido uno de los mayores lastres.

Podemos considerar como peruanistas a Felipe Guamán Poma de Ayala, Inca Garcilaso de la Vega, José de la Riva Agüero, Manuel Gonzáles Prada, Ricardo Palma, Raúl Porras Barrenechea, Aurelio Miro Quesada Sosa, Luis Alberto Sánchez, Jorge Basadre, Víctor Andrés Belaunde, José Carlos Mariátegui, Luis E. Valcárcel, José María Arguedas, Ciro Alegría, Jorge Cornejo Polar, Augusto y Sebastián Salazar Bondy, Alberto Flores Galindo y otros muchos más que vivieron una vida apasionada por la reflexión profunda del Perú, independientemente de sus inclinaciones políticas o ideológicas. Como puntualiza el arequipeño Cornejo (1996): 
A los estudiosos que han escogido el Perú, a la realidad peruana en algunos de sus variados aspectos, como el tema principal o preferente de sus trabajos, se les conoce tradicionalmente como peruanistas, de la misma forma en que, por ejemplo, se emplea el término de helenistas para designar a quienes han optado por el mundo griego como ámbito para el ejercicio de su quehacer intelectual (p. A3).

La pandemia no sólo desnudó de manera casi pornográfica nuestra precariedad institucional, desigualdades sociales y endebles sistemas de salud y educación, sino fundamentalmente la mentalidad nacional, la psicología nacional y los vicios mentales e idiosincráticos tan profundamente arraigados (inclusive a nivel inconsciente). En este sentido, no nos motiva un optimismo ingenuo, sino realismo y un análisis objetivo de nuestra psicología colectiva, que en la actual crisis sanitaria no hizo sino ahondar y llevar al paroxismo los problemas crónicos de la mentalidad peruana.

Por tal motivo, y para efectos del presente artículo, vamos a analizar esta problemática fundamentalmente a través de la mirada de dos peruanistas que, si bien pertenecen a generaciones diferentes, su esfuerzo intelectual e investigativo da luces en la forma de ser del Perú colectivo en los siglos XX y XXI. Pese a la diferencia temporal, se deja ver un hilo conductor y algunas persistencias históricas de nuestros defectos psicológicos nacionales. Estamos hablando en primer término de uno de los más preclaros peruanistas, Víctor Andrés Belaunde (1883-1966), cuyos ensayos diseccionan sociológica y psicológicamente el Ser peruano en tanto colectivo; básicamente en tres de sus más importantes obras, Meditaciones Peruanas, La realidad Nacional y Peruanidad. Un diagnóstico de la psicología peruana realizado durante las primeras décadas el siglo XX y orientado a un ideal: salvar el Perú. Porque bien sabía Belaúnde que nuestra mentalidad, la de las masas y la de los dirigentes, son la causa de nuestro atraso y subdesarrollo. Otro aporte en nuestro análisis es uno de los más destacados psicólogos sociales contemporáneos del siglo XXI, Jorge Yamamoto, quien el año pasado, producto de su sostenido trabajo de investigación empírica, publicó su libro La Gran Estafa de la Felicidad (2019), donde, desde la Psicología del Bienestar, revela las características de la identidad y mentalidad peruanas y revela cómo el bienestar psicológico del peruano (especialmente en las grandes ciudades) y su felicidad se han visto mermados por los vicios mentales colectivos, denominados antivalores por él. Así, se puede ver una secuela de improductividad económica, deterioro de la convivencia social, conductas antisociales (cuasi-ciudadanas) y corrupción a nivel social y estatal. Por eso, declara que su "libro no tiene un final feliz, pero sí un final desafiante y esperanzador" (Yamamoto, 2019, p. 22). En otras palabras, estos peruanistas demuestran la persistencia histórica de la inconsistencia psíquica de nuestra mentalidad nacional (nuestra subjetividad), debilitante de nuestro Ser Nacional y esto, en tiempos actuales de pandemia, se convierte en un lastre colosal. Por ello, debemos encontrar en sus reflexiones y hallazgos no el corrosivo efecto del optimismo ingenuo y pesimismo renunciante, sino la presencia de un pesimismo con escrúpulos, sustentado en la evidencia histórica, garantía y protección siempre contra el autoengaño (Scruton, 2010).

\section{La desviación de la conciencia nacional y la moral del anti-desarrollo sostenible}

La anatomía de la mentalidad nacional hecha por Víctor Andrés Belaunde es, expresado dramáticamente, penetrante; similar a adentrarse en los circuitos neuronales de un paciente. En este caso, un paciente llamado Perú. Belaunde reconoce la multiplicidad de factores influyentes en la configuración de nuestra conciencia nacional, como el económico, el político, el territorial y el racial, pero subordina todos estos al aspecto psíquico, donde encuentra una enraizada desorientación mental colectiva que nos conduce al abismo. La clase dirigente a lo largo de la historia, especialmente en la era republicana, se ha destacado por la incapacidad de llevar a cabo los grandes ideales y aspiraciones colectivas consecuentes a nuestra realidad nacional. Por el contrario, muchos dirigentes nacionales han 
asumido los asuntos públicos y nacionales con desviaciones psicológicas tales como el carácter mesiánico, el caudillismo y el personalismo, en el cual cada liderazgo se siente un "hito" histórico en el porvenir del país (García, 2003). Sin tomar en cuenta, claro está, aspectos psicopatológicos como la psicopatía clínica en muchos casos, con sumos ejemplos ilustrativos en presidentes y funcionarios públicos de los últimos 30 años, donde evidenciamos la existencia de una nueva clase política denominada por el psiquiatra polaco Andzrej M. Lobaczewsky (2013), patocracia. Es decir, sistemas de gobierno donde individuos con evidente síndrome psicopático de la personalidad se juntan y forman coaliciones para conseguir objetivos políticos, económicos y de poder comunes (Abarca, 2018). Es en esta línea Lobaczewsky (2013) da la siguiente definición: "adoptaré el término patocracia para designar a un sistema de gobierno creado de la manera descrita, dentro del cual una minoría patológica se apodera de las riendas de una sociedad de personas normales (p. 328). Entonces, así como existe la democracia o la aristocracia, está también la patocracia, sistema compuesto por uno de los trastornos antisociales más peligrosos para la vida moral y social de un país. Pero no sólo en el ámbito de la política es donde surge la presencia de coaliciones de personas con trastorno psicopático, sino también en el ámbito de los negocios, siendo el caso más emblemático de los últimos tiempos el de Odebrecht y los famosos clubes de la construcción (destrucción). Este ha sido el modus operandi histórico en el Perú, de contubernio entre malos funcionarios públicos y privados para llevar a cabo sus propósitos patocráticos. Lo demuestra así nuestro historiador peruano Alfonso Quiroz (2013) en su libro La historia de la corrupción en el Perú, las raíces de la gobernación corrupta en el Perú pueden rastrearse desde la época colonial y, a lo largo de la historia, se identifican generaciones de redes corruptas y violaciones sistemáticas a las reglas establecidas, comprometiendo no solo la actividad pública, sino también la privada. Quiroz (2013) define así la corrupción: "se entiende como el mal uso del poder político-burocrático por parte de camarilla de funcionarios, coludidos con mezquinos intereses privados, con el fin de obtener ventajas económicas o políticas contrarias a las metas del desarrollo social mediante la malversación o el desvío de recursos públicos, junto con la distorsión de políticas e instituciones" (2013, p.38). Vemos entonces la principal desviación moral nacional en las élites dirigentes.

Pero ¿qué pasa con la mentalidad nacional del peruano de a pie?, ¿por qué, finalmente, se impuso en el día a día la frase "el peor enemigo de un peruano es otro peruano" ?, ¿cuáles son las desviaciones de la psicología nacional del peruano común que imposibilitan a la fecha una nación con grandes ideales nacionales e intereses colectivos?

La profunda reflexión llevada a cabo por Víctor Andrés Belaunde en sus ensayos nos da luces de los modos de ser persistentes en el tiempo de los peruanos. García (2003), en su acucioso análisis de El pensamiento humanista de Víctor Andrés Belaunde, desentraña cada uno de ellos en su profundidad. Belaunde menciona como causa primaria de la crisis social del Perú el descuido de la moralidad, lo cual afecta nuestra identidad y personalidad insuficientemente definida, sin espacio para abocarnos a aspiraciones colectivas generales. En Meditaciones Peruanas (edición 1987), señala como defectos nacionales la falta de disciplina y sentimientos fuertes, la dejadez intelectual y la indiferencia, así como la incoherencia, rencores, ignorancia y el decoratismo. Somos de un carácter debilitado para la construcción de una obra colectiva, de ahí la primacía del individualismo. "Es la incoherencia la que explica la inferioridad de nuestra vida colectiva" (Belaunde, 1987, como se cita en García, 2003, p. 141). Verá también Belaunde en Nuestros rencores una inclinación por el murmullo y el chisme tendencioso. Desde la Psicología Social, esto coincide con el diagnóstico de Yamamoto (2019), quien evidencia una disminución del bienestar de los peruanos vinculado a la práctica cotidiana de antivalores como el egoísmo, la envidia y el chisme, triada social del mal (TSM) profundamente arraigada en la mentalidad del peruano. Por ejemplo, en su estudio publicado el 2014, más del $80 \%$ de los peruanos se auto-perciben como chismosos y "vivos criollos".

En esta línea, la profesora e investigadora social de la Universidad del Pacífico Liuba Kogan, indica que la hipocresía es algo muy presente en Lima y ha sido utilizada como estrategia de sobrevivencia en la 
"selva de cemento": a la gente le conviene más decir lo que el otro quiere escuchar a fin de obtener un rédito o beneficio. Pasa lo mismo con la "viveza criolla", pues cumple una función adaptativa ante una realidad donde no se respetan los derechos ciudadanos, ni existen reglas claras dentro de un contexto de pobreza y desigualdad (Integración, 2014).

Es acá donde encontramos la explicación del porqué en el día a día los peruanos encontramos sentido a la famosa frase "el peor enemigo de un peruano es otro peruano". Belaunde explica que a los peruanos nos gusta más el brillo, la apariencia, presumir y criticar. No queremos sobresalir, pero tampoco que otro sobresalga.

Yamamoto (2019) llega también a esta misma conclusión: “cuando un peruano progresa, el otro se siente miserable y contraataca con el chisme" (p.15). Sin embargo, se entiende esta actitud como un proceso de adaptación para regular la inequidad, es decir, "igualar la arena".

En esta misma orientación, en el año 1971, el sociólogo peruano Carlos Delgado en su artículo Ejercicio sociológico sobre el arribismo en el Perú, Problemas sociales en el Perú contemporáneo, donde el arribismo es producto de un sistema social dificultoso, lleno de trabas para una movilidad social fluida. El éxito social estaría restringido sólo a pequeños grupos o individuos y sería necesario recurrir al "patronazgo" e influencias personales. Por tanto, las posibilidades de éxito social se ven extremadamente reducidas y, ante la altísima competencia para acceder a posiciones de prestigio, poder o riqueza, la lucha por el triunfo social alcanza grados de alta ferocidad. En este sentido, toda arma vale.

Por tanto, "como todos quieren subir y hay pocas posibilidades de lograrlo, el ascenso de un individuo entraña el descenso de otro: sólo se puede "subir" cuando otro "baja” (Delgado, 1971, p. 195). Este deseo de ascender socialmente implica que nadie espontáneamente quiere descender, por eso se sube derribando a otros (traerse abajo otros).

Este afán desenfrenado de ascender, de "subir", es el arribismo, aliciente de "feudos" o "imperios personales" en los ámbitos sociales, laborales, políticos o empresariales. Es, entonces, una forma de conducta social estructuradora de relaciones sociales. Esta, según Delgado, tiene dos modalidades operativas: 1. la adulación genuflexa hacia quienes ostentan alguna posición de poder, conocido popularmente como el "sobe" y, 2. "el raje", o sea, el chisme, la agresión verbal indirecta, la crítica destructiva o los chistes peyorativos o burlones, zahirientes y de doble intención. El arribista raja de todo competidor real o potencial. Estas dos formas no son excluyentes y se practican de forma simultánea o alternada según las circunstancias.

Es en este punto donde Yamamoto (2019) encuentra otra conducta social del peruano sumamente corrosiva para el orden social cívico. La competencia desenfrenada por alcanzar éxito social, poder o status conlleva a la aparición de las famosas "argollas", es decir, conjunto de familiares y amigos con intereses comunes. Nada mal hasta aquí porque somos seres tribales por naturaleza, pero el problema según el investigador es la transformación de la lealtad a la argolla hacia una de tipo "cuasi-ciudadanía". Implica que se puede ir más allá de los derechos ciudadanos, el sentido de la justicia y el cumplimiento de la ley, no existen conflictos para favorecer a algún miembro, a costa de actos corruptos y antiéticos. Un caso muy ejemplificador fue el famoso escándalo de corrupción de los "hermanitos" del Tribunal Nacional de la Magistratura del año 2018, donde se hizo una exhibición de trato amable, altruista, solidario, muy empático, solicito y servicial, pero entre una argolla de magistrados, jueces supremos, jueces superiores, fiscales supremos y jueces superiores para fines personalistas y de grupo. Es aquí donde toma forma lo señalado por Delgado (1971) acerca de la aparición de "feudos" e imperios personales para lograr fines de status, poder, éxito y ascenso social.

Todo esto es lo que Víctor Andrés Belaunde llamaba los factores de la desviación de la conciencia nacional, motivo de nuestra inferioridad en la vida colectiva, colaboración casi nula excepto cuando somos arrebatados por la emoción pasajera del futbol. Como diría Chirif (2020): 
Tenemos un patriotismo de fantasía que se inflama, sobre todo, en eventos deportivos, en especial si el rival es el país que nos ganó la única guerra verdadera que ha tenido el Perú y que se perdió, sobre todo, por falencias propias: desunión, traiciones, falta de previsión, corrupción. Es decir, las mismas taras que hoy nos afectan (p.52).

Es parte de lo que Belaunde entiende como nuestra pobreza sentimental, hija de la incoherencia (pensar sin sentir hondamente) e incompatible con una vida sentimental uniforme; su manifestación está en la impresionabilidad y sensibilidad enfermiza, causa de nuestro sentimentalismo (falta de vigor de sentimiento, vivir de ilusiones, facilidad en el entusiasmo), una equivocada constitución psíquica de la sociedad peruana. Sin embargo, Yamamoto (2019) hace una aclaración sustancial ante este panorama: esta decadencia moral de la nación y la presencia persistente de la triada social del mal (egoísmo, chisme, envidia), tan profundamente arraigada en la mentalidad peruana, es un problema de las grandes ciudades urbanas del país, es decir, un problema de la Urbe. Los valores comunitarios y de bien común están presentes en los entornos rurales de la Sierra, la Amazonía y el Norte (comunidades rurales de pescadores), mientras las economías basadas en el comercio, la industria, con gran presencia de tecnología, internet e interacción anónima entre miles y millones de personas en el día a día, promueven la competencia y valores de corte individualista. Por tanto, la equidad, la vida comunitaria y el bien común no son funcionales para las metas de progreso material de individuos y familias, que buscan incesantemente el éxito social. Se genera con ello un "mega-individualismo" e "hiper-competencia", además de un estilo de vida hedonista, la búsqueda constante de emociones, placeres inmediatos y consumo. Al final, si bien se logran concretar estos ideales, traen consigo vida solitaria, vacío existencial, depresión e infelicidad: "la estafa de la felicidad" en la sociedad moderna urbana peruana y latinoamericana. De ahí que tome forma la famosa frase de una canción popular, "la calle es una selva de cemento".

Esto sin duda es un problema de la modernidad, profundamente analizado por el psicoanalista y sociólogo judío-alemán Erich Fromm (1900-1980), quien plantea que todas estas conductas sociales llegan a normalizarse en las grandes ciudades, de ahí que acuñe el término de "patología de la normalidad", nombre de su libro póstumo.

Si en las grandes ciudades del Perú y Latinoamérica se ha normalizado durante décadas las conductas sociales analizadas por Belaunde, Delgado, Yamamoto, Chirif o Kogan, significa que la práctica de los antivalores se ha convertido en una forma "normal" y natural de convivencia social entre los ciudadanos, una forma de convivencia social insana, generadora de conflictos y poco o nada saludable desde el punto de vista cívico; lo cual evidencia, justamente, la desviación de la conciencia nacional y la moral del antidesarrollo sostenible. Como anunciaba Fromm, se trata de una "patología de la normalidad", es decir, del hombre "normal" socialmente adaptado a la vida en la ciudad, con actitudes y rasgos de carácter social que lo enferman mentalmente. Lo funcional y positivo para el modelo económico y social de la urbe, resulta nocivo y negativo para la salud mental del ciudadano. El precio a pagar en la ciudad por el éxito social, el status, el progreso económico, el consumismo y el hedonismo es el deterioro de la salud mental, lo cual termina en una evolución morbosa (Funk, 1991). Un ejemplo de Fromm (1995) sobre esta "patología" es la "orientación mercantil" de las personas. El hombre no sólo vende su fuerza física o su capacidad cuando aplica a algún trabajo, también oferta su personalidad, es decir, debe ser agradable para el mercado y ajustar sus actitudes a un modelo impuesto por la sociedad de mercado, dejando su humanidad y pasando a convertirse en una mercancía, para lo cual debe cultivar ciertas cualidades que lo hagan cotizable en el mercado. Si es cotizable tiene éxito, si no se sentirá un fracasado. Así la confianza personal no depende de sus virtudes inmanentes como ser humano (sinceridad, integridad, humor, etc.), 
sino de su éxito en la competencia de posicionar su imagen en el mercado, o sea, en su éxito de ventas. Siempre perseguirá el éxito y, si este no le es favorable, se volverá frenéticamente inseguro.

En las grandes ciudades, millones de personas comparten consciente o inconscientemente este tipo de conductas sociales, causa de su normalización. En otras palabras, se hacen conductas sociales compartidas, aceptadas, toleradas y "consensuadas" silenciosamente, pero no por ello están relacionadas con la racionalidad y la salud mental. Por ende, están equivocados quienes sustentan que una sociedad es normal porque funciona y, tampoco, la patología se define por la poca capacidad del individuo para "adaptarse" a un tipo de convivencia social. Fromm lo aclara así: "El hecho de que millones de personas compartan los mismos vicios no convierte esos vicios en virtudes; el hecho de que compartan muchos errores no convierte a éstos en verdades, y el hecho de que millones de personas padezcan las mismas formas de patología mental no hace de esas personas gentes equilibradas" (Fromm, 1995, p. 20).

\section{¿Qué hacer?}

Ante esta realidad psíquica del Ser nacional, siguiendo el espíritu de Belaunde, surge entonces la pregunta capital ¿Cómo orientar el espíritu nacional para que se propaguen los ideales colectivos de la patria en la era del pos-bicentenario?, ¿cuáles serán nuestros ideales salvadores?, ¿cuáles serán nuestras nuevas aspiraciones nacionales?

Lo que vive el Perú en esta crisis sanitaria es un desastre a nivel de sistema de salud, sistema educativo y con severas consecuencias económicas y sociales. Pero, de cara el bicentenario podría convertirse en una oportunidad de refundación del Ser nacional, el mismo reclamo de Belaunde en otro momento histórico de crisis y desastre, la guerra con Chile: "Sin embargo, no surgió después de la guerra aquél afán de estudio, aquel impulso radical de renovación. Nada hubiera sido más justo ni nada más explicable que se hubiera discutido, después del desastre, las nuevas bases de la vida política y económica del Perú" (Belaunde, 1987, como se cita en García, 2003, p. 151). En este sentido, coincidimos con García (2003), ante una catástrofe (la guerra en aquellos años) como la actual crisis sanitaria, económica, social y política no podemos seguir viviendo con el mismo ambiente moral y con la misma arquitectura política, económica, educativa y de salud que nos ha llevado al abismo una vez más. Para no caer en él, Belaunde (1931) nos insta a la "necesidad de una filosofía constructiva".

Como peruanista predilecto, cuya única vocación y destino fue su país, nos señala la única hoja de ruta moral plausible para los peruanos: "(...) sume todas las voluntades rectas, que atraiga a todos los espíritus bien intencionados. Sólo una condición: absoluta honradez. Sólo un ideal: salvar al Perú" (Belaunde, 1931, p. 358). En el plano organizativo nos delinea una base de acción política de la peruanidad, con la sabiduría de su profundo conocimiento del Ser Peruano y su alma idealista. Esto lo detalló en su discurso de orden, en la actuación central conmemorativa del XXV aniversario de la fundación de la Pontificia Universidad Católica del Perú, pronunciado en 1942:

Formemos un frente único y común sobre la roca de certidumbres éticas y religiosas eternas y de un programa de reforma social a base del respeto de la dignidad de la persona humana, igualmente alejado de los extremos del conformismo y de la utopía, de la anarquía individual y de la omnipotencia estatal, exaltando los valores comunes de nuestra cultura y creemos el frente único de la peruanidad (Belaunde, 1942, como se cita en García, 2003, p. 130).

Pero, ¿cuál sería la finalidad suprema de esta ética capital y organizativa que nos hereda Belaunde? El arequipeño sostiene la existencia de problemas sociales urgentes y de intensa preocupación ético-social, ve la causa primaria de la crisis del Perú en el descuido de la moralidad, la deficiente formación del carácter del peruano (Belaunde, 1931), producto de una pésima administración de la educación. Por otro lado, 
Yamamoto, a través del sostenido trabajo de investigación de la identidad peruana, arriba a la misma e irreductible lógica al sostener la bajeza en las defensas morales del país y la ocupación céntrica de los antivalores en la creciente infelicidad y caos nacional. Si esto ha logrado ganar terreno de manera tan dramática en el Perú, no es ya una arbitrariedad de la cultura peruana y latinoamericana, sino de una rotunda separación de la naturaleza humana. Existe un cableado cerebral estructurado en la profunda naturaleza humana y moldeado a través de nuestra evolución ancestral. Esta antiquísima herencia es la colaboración del colectivo para la sobrevivencia, desaparecida por la vida ultramoderna, ultra individualista y de hiper-competencia de las grandes ciudades.

Por lo tanto, la finalidad suprema de esta ética capital y organizativa, herencia de Belaunde y necesidad nacional planteada por Yamamoto, es la re-fundación profunda de la psicología nacional; en palabras de Belaunde, implica la reorientación de la equivocada constitución psíquica de la sociedad peruana: la formación del carácter no ideológica, cognitiva, religiosa ni empresarial, sino "herencia espiritual, la formación de los primeros años y el ambiente familiar" (Belaunde, 1931, p. 354). Y ¿por qué el carácter? porque es el componente ético de la personalidad y permite la auto-regulación del comportamiento a través de las convicciones morales. Desde el punto de vista neurológico, implica la acción educativa para lograr la mayor conectividad neuronal y dendrítica para el desarrollo de los lóbulos pre-frontales del cerebro, quienes regulan el comportamiento humano con la consciencia ética.

Yamamoto (2019) nos habla de una verdad axiomática: En el Perú “los antivalores constituyen las raíces del anti-desarrollo sostenible (...) es una de las peores y silenciosas epidemias que está matando el progreso de la región" (... "una mejora de la economía con antivalores resulta en una combinación muy peligrosa" porque "cuando una persona se ve afectada por la conducta de antivalores de los otros, tiende no solo a dejar de comportarse de acuerdo con los valores, sino que rápidamente llega a disfrutar el devolver el antivalor al otro". Sostiene que los valores no cambian con talleres, cursos, buenos consejos o inducciones en las empresas, o con unos años de formación en las universidades. Esto no modifica las estructuras cerebrales. Las estructuras cerebrales se establecen en valores para siempre con la formación correcta de los hijos (Yamamoto, 2019). En palabras de Belaúnde: "la herencia espiritual, la formación de los primeros años y el ambiente familiar” (Belaúnde, 1931, p.354).

Por tanto, para Yamamoto, la solución no puede ser otra: forjar valores en la niñez y estabilizarlos en la adolescencia, pero con una válida aclaración, los valores en el Perú a reflexionar y cambiar no deben ser sobre ideales de comportamiento abstracto, sino de axiomas realmente existentes en el Perú actual.

Pero ¿qué prioriza el sistema educativo en el Perú? Conocimientos, cognición, competencias académicas evaluadas por la prueba PISA (comprensión lectora, matemáticas, ciencias), futuras competencias laborales necesarias para la empleabilidad y la inserción exitosa en el mercado. Es decir, un sistema acorde a las exigencias económicas y sociales de la modernidad en las grandes ciudades basadas en la orientación mercantil, el mega-individualismo, la hiper-competencia, la búsqueda de éxito social, estatus, progreso material, capacidad adquisitiva, consumo y hedonismo.

Entonces, ¿Qué tipo de educación necesitamos en el Perú bicentenario para la re-fundación profunda de la psicología nacional y la reorientación de la equivocada constitución psíquica de la sociedad peruana; para formar el carácter de los peruanos; para que los antivalores no constituyan las raíces de nuestro antidesarrollo sostenible; para que la práctica de los antivalores no siga siendo la peor y silenciosa epidemia que mata nuestro progreso; para que futuras pandemias y futuras mega-crisis no generen una catástrofe social y económica como la que hoy padecemos; para que los peruanos en tiempos de crisis no salgan a comprar cerveza y no condenen con racismo a los que tuvieron que priorizar el no morir de hambre antes que al contagio; para que el Perú deje de ser un país bajo en defensas morales; para dejar de ser una promesa incumplida; para generar un nuevo contrato social cívico-educacional?, ¿cuál será nuestra nueva mística, el nuevo centro de gravedad espiritual del Ser Nacional después del bicentenario?, ¿necesitamos 
ser más consumidores que ciudadanos o más ciudadanos que consumidores?, ¿necesitamos más coaches para la empleabilidad o más coaches para la virtud?

Las respuestas nos permitirán encontrar el sentido nacional para la refundación moral y educacional del Ser nacional, es decir, una nueva voluntad colectiva, un nuevo contrato social en la concepción de Rousseau; donde, para refundar el Perú-bicentenario bajo un nuevo pacto social, se requiera el consentimiento unánime entre el Estado, las políticas educativas estatales, la inversión en la refundación educacional, la comunidad educativa, maestros, profesores y las familias. En esta dinámica nacional se encontrarán los grandes ideales para la nueva mística y el nuevo centro de gravedad espiritual del Ser nacional.

Necesitamos una educación para ser una República con ciudadanos y no sin ellos.

En esta dirección no he encontrado forma más hermosa de expresar la misión de la educación para los primeros años de vida del ser humano (aplicable a cualquier nación que tenga como destino y vocación colectiva su Ser Nacional) que las palabras pronunciadas por el arequipeño y fundador de nuestro hospital Goyeneche, Juan Mariano de Goyeneche y Gamio (1835-1924) en Lima (1859), su discurso titulado La educación de la Juventud con motivo de su recepción de socio en la Academia Lauretena de Arequipa:

Reformemos la educación de la juventud, y reformaremos el género humano, la buena educación de la juventud es el primer fundamento de la felicidad humana. Tales son las palabras del célebre Leibnitz (...) La educación ejerce una influencia decisiva sobre el niño y la familia, que son los primeros elementos de toda sociedad: crea y determina las costumbres domésticas, inspira las virtudes sociales, dispone y allana el camino para la reforma y rehabilitación intelectual, moral y religiosa de un pueblo. La educación hace los pueblos, porque hace los individuos, a quienes da y transmite, con las ideas, la razón en su uso y desarrollo. Un pueblo es como el individuo: lo que fue su educación. Si esta fue sana, profunda y cristiana; corresponderá a sus fines, y será humana y social; si viciosa, pedante, insuficiente o sectaria, entonces será antisocial, factor y creadora de todos los males, y el medio más seguro para embrutecer las inteligencias, falseando los principios de lo justo, para facilitar el triunfo de la violencia y de la tiranía. (... ) La educación, primera Ley constitutiva y generadora de la sociedad en todos sus estados, tiene por fin supremo cultivar; esto es, trabajar, fortificar y dirigir todas las fuerzas físicas, intelectuales y morales; en una palabra, formar al hombre (...) Así preparamos y formamos al hombre para el servicio de la patria, en las diversas funciones sociales, que deberá desempeñar en seguida en el periodo de su fugaz existencia (Goyeneche, 1859, pp. 10-14).

Víctor Andrés Belaunde y Jorge Yamamoto entendieron las defensas morales del hombre en la niñez, pero Juan Mariano de Goyeneche lo expresa con bella verdad:

Para comprender toda la trascendencia de esta doctrina habremos de preguntarnos ¿Qué es un niño? Es el género humano, es la humanidad; es el hombre con un derecho imprescriptible al cuidado, a la atención, a los desvelos, a la solicitud de todo poder humano, así como a su protección y a sus beneficios. Toda autoridad divina o humana, el Sacerdote y el Príncipe, el Padre y el Maestro, el Magistrado y el militar, la familia, la sociedad, todo existe por él y para él (...) Así pues todo ha de servir y cooperar a su conservación y a su desarrollo; esto es, a su educación. He aquí la grande obra que nace en el seno de la familia, y ha de terminar en el seno del mismo Dios (1859, pp. 15-16). 


\section{Conclusiones}

Cuando mentes tan preclaras del Perú expresan lo siguiente: "El Perú es un cuerpo enfermo que donde se pone el dedo salta la pus" (Manuel Gonzáles Prada); "en el Perú lo que no da asco, da risa" (Expresidente, Riva Agüero); "el Perú es un Burdel” (Pablo Macera); "los peruanos parecemos poseídos por un extraño demonio de corrupción pública, que todo lo mancha y desvirtúa” (Luis Alberto Sánchez); "que el Perú se escape de no ser sino una charca, de volverse un páramo o de convertirse en una fogata" (Jorge Basadre); "la corrupción en el Perú ha logrado hacer metástasis" (Sinesio López); "somos un país que no conoce de diálogo alturado y mucho menos la construcción de proyectos a largo plazo" (Carmen Mc Evoy); "hemos sido incapaces de sacar el país de la inercia anti-institucional, aun cuando era urgente hacerlo" (Alberto Vergara); y si la famosa frase popular "el peor enemigo de un peruano es otro peruano" ha calado tanto en el imaginario social de los peruanos, es porque definitivamente tenemos la promesa del Perú no cumplida y se escucha en nuestra consciencia la voz del ayacuchano Felipe Guamán Poma de Ayala, cuando en su Nueva Crónica y Buen gobierno (1969) repite una y otra vez su lamento "y no hay remedio".

La hipótesis del Perú como promesa no cumplida se confirma con la verdad de la evidencia histórica; quien más para confirmarla si no es el historiador Quiroz (2013) en el libro más importante escrito sobre la Historia de la Corrupción en el Perú, producto de un trabajo incansable y monumental, donde demuestra que "en el Perú, la corrupción no era algo esporádico sino, más bien, un elemento sistémico, enraizado en estructuras centrales de la sociedad" (...) y "de cómo en abuso de la corrupción influyó en la evolución histórica de un país subdesarrollado" (p. 31).

Pero el psicólogo peruano Jorge Yamamoto (2019), producto de su sostenido trabajo investigativo, descubre a la corrupción no solo en la estructuras y las instituciones peruanas, también en la mentalidad peruana, en la convivencia social cotidiana del peruano de a pie, lo que él llama el comportamiento social cuasi-ciudadano, la normalización de la práctica de los antivalores en el día a día de los peruanos, diagnóstico prematuro algo del gran peruanista Víctor Andrés Belaúnde en las primeras décadas del siglo $\mathrm{XX}$.

Este examen le permite hablar a Belaúnde de las deformaciones de nuestra conciencia histórica y de la equivocada constitución psíquica de psicología nacional, fruto del descuido de la moralidad como causa primaria de la crisis en el Perú. De ahí que Yamamoto señale al Perú como un país bajo en defensas morales, causa del fallo en cumplir la promesa del Perú como colectivo. Más bien, hemos logrado cumplir nuestras promesas individuales a nivel de progreso material, de consumo individual y familiar.

En la mentalidad del peruano no está cambiar su país, sino cambiar su automóvil, su estatus y tener éxito social, las exigencias de la sociedad hiper-moderna en las grandes ciudades, donde el sentido y contenido de la vida lo da la búsqueda del vivir bien (poder adquisitivo), mas no del buen vivir (comportamiento cívico saludable). Son el mega-individualismo y la hiper-competencia el contexto social urbano subyacente a la presencia sostenida de los antivalores de la envidia, el chisme y el egoísmo (triada social del mal) en la convivencia cotidiana en las grandes ciudades del Perú. De ahí que se hable sobre la nueva "patología de la normalidad peruana".

Convenimos entonces con Sinesio López, la corrupción hizo metástasis en el Perú. Por tanto, ya no estamos ante una promesa incumplida llamada Perú, sino ante un paciente llamado Perú. La enfermedad es grave y crónica.

Por ende, tenemos ante nuestros ojos el desafío más severo de cara al bicentenario, resumido en lo planteado por Víctor Andrés Belaunde: salvar al País. Esto implica preguntarnos ipasadas las festividades protocolares del bicentenario, vamos a tener un centenario más, o un bicentenario más, 
arrastrando el lamento "y no hay remedio" de Guamán Poma; una promesa peruana sin cumplir; la nueva patología de la normalidad peruana; la desviación de nuestro Ser nacional?

El Perú necesita una refundación de su Ser nacional, las claves para ello las hemos analizado a lo largo del trabajo. Porque, si no se refunda el Ser nacional, probablemente alguno de nuestros nietos escribirá en el futuro un ensayo llamado: "Los trecientos años de una promesa sin cumplir".

\section{Referencias}

Abarca, J. (2018) Psicopatología política y del poder como fundamento psicológico de la corrupción en el Perú. Revista de investigación La Salle Universidad, 7(19), 5-26.

Agüero, J. C. (2020). Memoria del futuro. En Bicentenario del Perú. En G. Perona (Ed.), 25 ensayos desde la pandemia para imaginar el Perú Bicentenario (pp. 28-38). Bicentenario del Perú.

Belaunde, V. (1931). La realidad nacional. París, Francia: Le Livre Libre.

Byung-Chul, H. (2014). La agonía del eros. Barcelona, España: Herder.

Chirif, A. (2020). El virus que desnuda. En Bicentenario del Perú. En G. Perona (Ed.), 25 ensayos desde la pandemia para imaginar el Perú Bicentenario (pp. 46-56). Bicentenario del Perú.

Conexión ESAN (24 de abril de 2020). Impacto del COVID-19 en el empleo en el Perú. Conexión ESAN.

Recuperado de: https://www.elperuano.pe/noticia-impacto-economico-de-pandemia-dejara-unbache-profundo-la-region-97059.aspx

Cornejo, J. (31 de agosto de 1996). Los peruanistas y la imagen del Perú. El comercio, A3.

Delgado, C. (1971). Ejercicio sociológico sobre el arribismo en el Perú. Problemas sociales en el Perú contemporáneo. En Agenda Perú. (Ed.) Los 50 y tantos libros que todo peruano culto debe leer (pp. 195-197). Bicentenario del Perú.

Guamán, P de A. F. (1969). Nueva crónica y buen gobierno. Perú: Casa de la cultura del Perú.

Flores, G. (1997). República sin ciudadanos. Revista Fronteras, 1(1), 13-33.

Fromm, E. (1995). La patología de la normalidad. México: Paidós.

Funk, R. (1991). Prólogo. En La patología de la normalidad (pp. 11-16). México: Paidós.

García, G. (2003). El pensamiento humanista de Víctor Andrés Belaúnde (Tesis de maestría). Universidad de Piura, Perú. Recuperado de

https://pirhua.udep.edu.pe/bitstream/handle/11042/2278/MAE_EDUC_039.pdf?sequence=1\&isAll owed $=\mathrm{y}$

Goyeneche, J. M. (1859). Discurso sobre la educación de la juventud. Biblioteca Nacional del Perú.

Integración (setiembre de 2014). Informe en busca de la identidad peruana. ¿Cómo nos vemos los peruanos? Recuperado de https://www.studocu.com/pe/document/universidad-de-lima/eticacivica/s3-lectura-informe-en-busca-de-la-identidad-peruana/14043394

Lobaczewsky, A. (2013). La ponerología política. Una ciencia de la naturaleza del mal adaptada a propósitos políticos. Varsovia, Polonia: Pilule Rouge.

Nugent, G. (2020). Doscientos años a través de cuarenta días: cómo afirmar nuestra consistencia social. En Bicentenario del Perú. En G. Perona (Ed.), 25 ensayos desde la pandemia para imaginar el Perú Bicentenario (pp. 148-156). Bicentenario del Perú.

Orrego, A. (1929). ¿Cuál es la función de pensar? Revista Amauta, 27.

Quiroz, A. (2013). Historia de la corrupción en el Perú. Lima, Perú: Instituto de Estudios Peruanos.

Sánchez, L. A. (1963). El Perú: retrato de un país adolescente. Lima, Perú: Universidad Nacional Mayor de San Marcos.

Scruton, R. (2010). Usos del pesimismo. El peligro de la falsa esperanza. España: Ariel.

Vergara, A. (2018). Ciudadanos sin república. De la precariedad institucional al descalabro político. Perú: Planeta.

Yamamoto, J. (2019). La gran estafa de la felicidad. Perú: Planeta. 